\title{
Synthesis of aligned and length-controlled carbon nanotubes by chemical vapor deposition
}

\author{
Young Soo Park ${ }^{1,2}$, Hyung Suk Moon ${ }^{3}$, Mongyoung Huh², Byung-Joo Kim², Yun Su Kuk ${ }^{2,4}$, Sin Jae Kang ${ }^{2,5}$, \\ Seong Hee Lee ${ }^{1}$ and Kay Hyeok An ${ }^{2, \$}$ \\ ${ }^{1}$ Department of Polymer-nano Science and Technology, Chonbuk National University, Jeonju 561-756, Korea \\ ${ }^{2}$ Korea Institute of Carbon Convergence Technology, Jeonju 644-841, Korea \\ ${ }^{3}$ AFFC Co., Jeonju 561-844, Korea \\ ${ }^{4}$ Department of Organic Materials and Fiber Engineering, Chonbuk National University, Jeonju 561-756, Korea \\ ${ }^{5}$ Department of Mechanical Design Engineering, Chonbuk National University, Jeonju 561-756, Korea
}

\section{Article Info}

Received 5 January 2013

Accepted 21 February 2013

*Corresponding Author

E-mail: khan@jmc.re.kr

Tel: $+82-63-219-3700$

\section{Open Access}

DOI: http://dx.doi.org/

10.5714/CL.2013.14.2.099

This is an Open Access article distributed under the terms of the Creative Commons Attribution Non-Commercial License (http://creativecommons.org/licenses/ by-nc/3.0/) which permits unrestricted non-commercial use, distribution, and reproduction in any medium, provided the original work is properly cited.

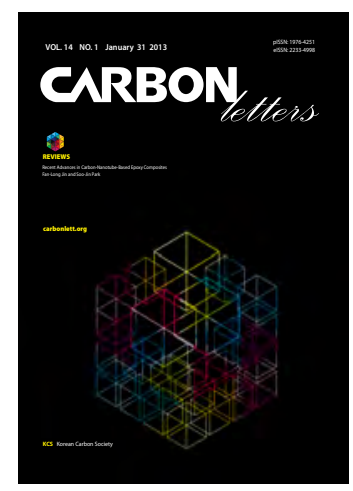

http://carbonlett.org

pISSN: $1976-4251$

elSSN: 2233-4998

Copyright $\odot$ Korean Carbon Society

\begin{abstract}
We investigated the effects of parametric synthesis conditions of catalysts such as sintering temperature, sorts of supports and compositions of catalysts on alignment and length-control of carbon nanotubes (CNTs) using catalyst powders. To obtain aligned CNTs, several parameters were changed such as amount of citric acid, calcination temperature of catalysts, and the sorts of supports using the combustion method as well as to prepare catalyst. CNTs with different lengths were synthesized as portions of molybdenum and iron using a chemical vapor deposition reactor. In this work, the mechanisms of alignment of CNTs and of the length-control of CNTs are discussed.
\end{abstract}

Key words: carbon nanotube, alignment, length control, chemical vapor deposition

\section{Introduction}

Since their discovery in 1991, carbon nanotubes (CNTs) have attracted considerable attention from the scientific community and industry. CNTs are recognized as ideal reinforcing fillers for polymers due to their unique mechanical properties and high aspect ratio [1]. CNTs have high values of strength and modulus, of almost $200 \mathrm{GPa}$ and 1 $\mathrm{TPa}$, respectively [2-4]. Many studies have been devoted to the manufacture of CNTreinforced polymer composites. Nevertheless, there have been a lot of problems that have occurred from entangled CNTs in three dimensions. So, CNTs should be cut and then dispersed in a composite matrix [5-7]. One alternative from the perspective of CNT dispersions has been both short and aligned CNTs. The powder form of short and aligned CNTs can be more easily dispersed in a composite matrix than can be normally grown CNTs. Several researchers [8-14] have succeeded in growing aligned CNTs powders, but there has been no fabrication of a composite with aligned CNTs. Current materials do not seem to be suitable for composites because of the use of high temperature in the CNT growth and high molybdenum contents in the catalysts. And, there have been only a few trials to control CNT length $[15,16]$. In previous reports, the amounts of produced CNTs were not sufficient to carry out a composite study on CNT lengths. To determine the exact effect of CNT length on the mechanical and electrical properties of CNTreinforced composite, length controlled CNTs need to be synthesized.

The purpose of this work is to achieve the synthesis of aligned and length-controlled CNTs with high yield and product and to establish their mechanism, simultaneously. 


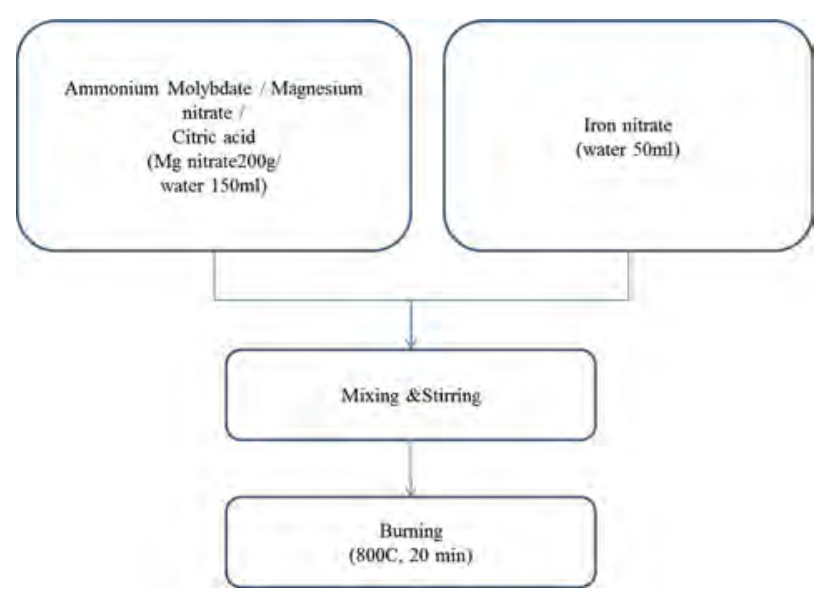

Fig. 1. Procedure of preparing catalysts.

\section{Experimental}

\subsection{Materials}

For the synthesis of catalysts, iron nitrate, magnesium nitrate, ammonium molybdate and citric acid were all extra pure grade (SamJeong Chem., Korea) and were used without further treatment. Five different components of Fe-Mo co-catalysts in $\mathrm{MgO}$ support were prepared using the combustion method.

\subsection{Preparing and pelletizing aligned CNTs}

The catalyst was prepared using the combustion method. $\mathrm{Mg}\left(\mathrm{NO}_{3}\right)_{2} 6 \mathrm{H}_{2} \mathrm{O},\left(\mathrm{NH}_{3}\right)_{6} \mathrm{Mo}_{7} \mathrm{O}_{24} 4 \mathrm{H}_{2} \mathrm{O}, \mathrm{Fe}\left(\mathrm{NO}_{3}\right)_{3} 9 \mathrm{H}_{2} \mathrm{O}$ and citric acid were dissolved in hot distilled water. Five different proportions of $\mathrm{Fe} / \mathrm{Mg} / \mathrm{Mo}$ were prepared with fixed molar ratio of $\mathrm{Mg}$; we changed the ratios of Mo and Fe through a certain procedure, as follows. First, molybdenum hydrate was dissolve in pre-heated water. Then, magnesium nitrate and citric acid were added to the aqua solution, in order. And, the separately-prepared iron aqua solution was poured into the solution in which molybdenum, magnesium and citric acid were solved. Finally, the catalyst powders were obtained when the resulting solutions were burnt in air at $800^{\circ} \mathrm{C}$ for $20 \mathrm{~min}$. A more detailed description of the preparation of the catalyst is shown in Fig. 1. The chemical vapor deposition (CVD) reactor was heated to $650^{\circ} \mathrm{C}$; then, the catalysts in amounts from $1 \mathrm{~g}$ to $10 \mathrm{~g}$ without grinding were inserted into the center in order to grow aligned CNTs. The mixture of $\mathrm{C}_{2} \mathrm{H}_{4}$ and $\mathrm{H}_{2}$ at a flow rate of $4000 \mathrm{sccm}\left(\mathrm{C}_{2} \mathrm{H}_{4} / \mathrm{H}_{2}=3: 1\right)$ was introduced into the tube. After $60 \mathrm{~min}$ reaction, the $\mathrm{C}_{2} \mathrm{H}_{4} / \mathrm{H}_{2}$ was shut off and the system was cooled to room temperature.

Synthesized CNT samples had different amounts of CNTs, but the samples were used without further chemical treatment. It was not easy to compound polymers with aligned CNTs, because the densities of the aligned CNTs, which ranged from 0.01 to $0.04 \mathrm{~g} / \mathrm{cc}$, were too much smaller than those of polymers. To make the pellets similar to thermoplastic polymers, all CNT samples were first ground with a mixer and simply mixed with
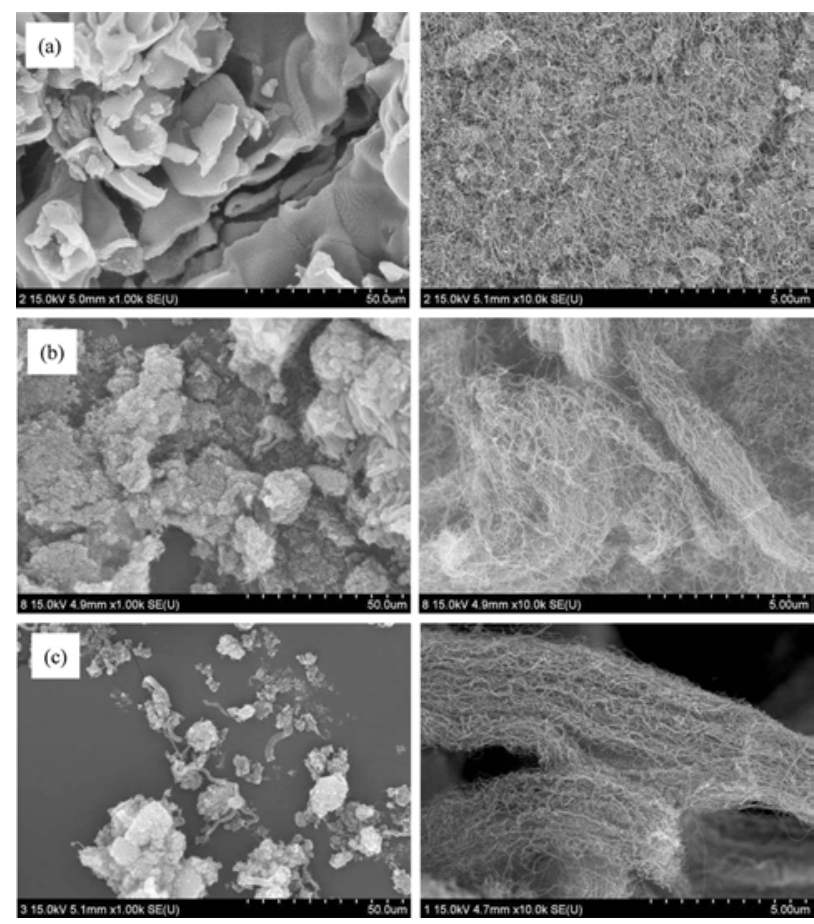

Fig. 2. Images of scanning electron microscope for as-grown carbon nanotubes according to the weight ratio of citric acid to magnesium nitrate: (a) 0.5 , (b) 1.0 and (c) 2.0 .

water (the ratio of water to CNTs was 10 to 1 ). Then, pelletized CNTs were made by passing the material through a home pelletizer and drying samples at $120^{\circ} \mathrm{C}$ for $12 \mathrm{~h}$.

The synthesized CNTs were analyzed using an scanning electron microscope (SEM) to determine the morphology of the CNT powders; using a transmission electron microscope (TEM) to determine the averages and distributions of diameters; using a Raman spectroscope to determine the crystalline properties of the CNTs; and using thermo-gravimetric analysis (TGA) to determine the purity of the CNT powders.

\section{Results and Discussion}

To obtain aligned CNT powders, we changed the amounts of citric acid, while maintaining fixed proportions of metal catalysts and supports, and fixed synthesis temperature of the catalysts. The ratio of citric acid to magnesium nitrate was increased in increments of 0.5 from 0.5 to 2.0. All CNTs were grown at $650^{\circ} \mathrm{C}$. When the ratio reached 1.0, aligned CNTs began to appear. But, even when the ratio was 2.0, the morphologies of the samples were similar to those when the ratio was 1.0 , as shown in Fig. 2. So, we changed the preparing temperature of the catalyst from 600 to $800^{\circ} \mathrm{C}$. Fig. 3 provides SEM images of the as-grown CNTs with catalysts synthesized using the same ratio of metal contents to $\mathrm{MgO}$ supports with different synthesis temperatures. The CNTs shown in Figs. 3a-c were grown at $650^{\circ} \mathrm{C}$ in an atmosphere of ethylene and hydrogen gas for $1 \mathrm{~h}$ using catalyst/supports synthesized at $600^{\circ} \mathrm{C}, 700^{\circ} \mathrm{C}$ and $800^{\circ} \mathrm{C}$, respectively. It can be seen that there were no aligned CNTs grown 

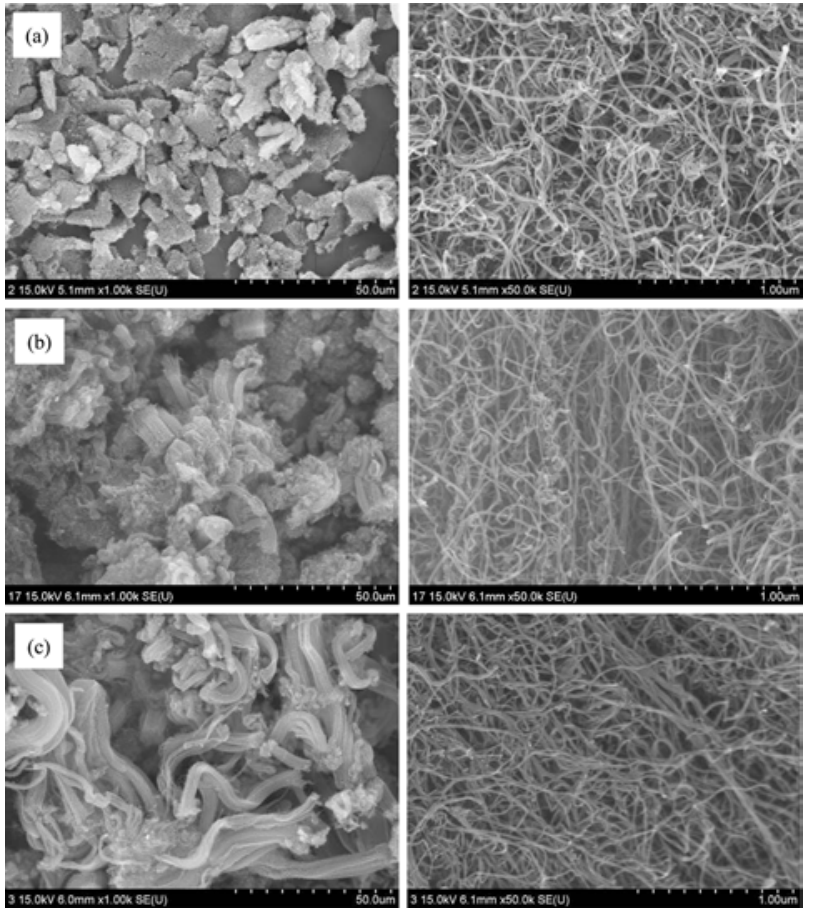

Fig. 3. Images of scanning electron microscope for as-grown carbon nanotubes due to preparing temperature of catalysts: (a) $600^{\circ} \mathrm{C}$, (b) $700^{\circ} \mathrm{C}$ and (c) $800^{\circ} \mathrm{C}$.

on the catalysts synthesized at $600^{\circ} \mathrm{C}$ at all, but a small quantity of CNTs were aligned on the catalyst at $700^{\circ} \mathrm{C}$. Finally, it seems that most CNTs on the catalyst at $800^{\circ} \mathrm{C}$ were well aligned in one direction. With the increase of the temperature for the preparation of the catalysts, besides the alignment of CNTs, the yields of CNTs were also increased as much as 2000, 3000 and 6000 $\mathrm{wt} \%$, in the order of Figs. 3a-c, as can be seen in Fig. 3. It was analogized that the amounts of metal nanoparticles compared to the grown CNTs were enriched due to the increase of the preparation temperature of the catalysts. According to the papers of Lie et al. [13] and those of several other researchers [14-16], the catalysts for aligned CNTs were calcined at a temperature of more than $750^{\circ} \mathrm{C}$. Those researchers reported that the growth mechanism of the aligned CNTs grown over molybdenum/magnesium oxide or iron, nickel, and cobalt doped molybdenum/ magnesium oxide catalysts, in which the absorption of hydrogen makes the molybdenum nanoparticles separate out from the inside to the outside of the catalyst, led to the formation of multilayers of molybdenum nanoparticles on the surface of the support. This explanation was not suitable for our study, because those researchers used molybdenum as a catalyst for the synthesis of aligned CNTs, and, even though they introduced iron or nickel, cobalt as catalysts, the contents of those catalysts were less than 10 molar \% molybdenum. The growth mechanism of the aligned CNTs on the iron-rich catalyst or molybdenum-poor catalyst, such as were used in our study, would be similar to that of aligned growth on a substrate such as silicon wafer. This means that the metal nanoparticles such as $\mathrm{MgO}$ could easily melt and then move from the inside of the ceramic supports to the surface of the ceramic supports when catalysts were synthe-
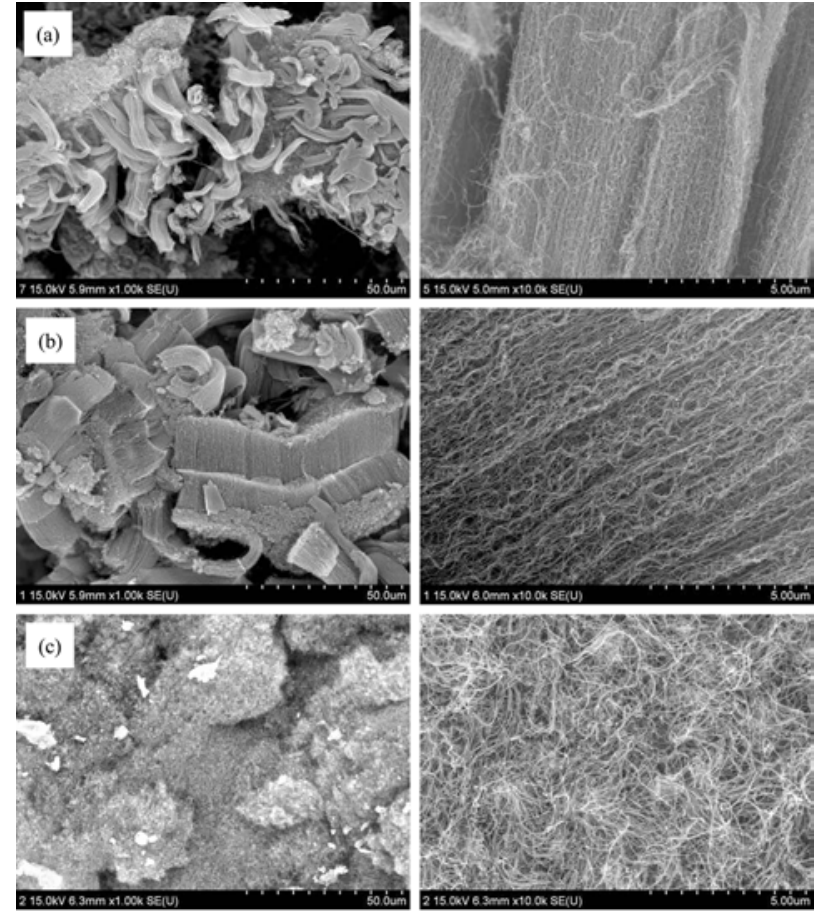

Fig. 4. Images of scanning electron microscope for as-grown carbon nanotubes with changing the supports: (a) magnesium oxide, (b) aluminum oxide and (c) calcium oxide.

sized at the temperature of $800^{\circ} \mathrm{C}$

To determine the effect of the supports on the synthesis of aligned CNTs, support precursors were changed to aluminum nitrate, calcium nitrate and manganese nitrate instead of magnesium nitrate. All catalysts were combusted under the same temperature of $800^{\circ} \mathrm{C}$, as previously mentioned. Fig. 4 provides SEM images of the as-grown CNTs on different supports in order of magnesium oxide, aluminum oxide, and calcium oxide. In the cases of magnesium oxide and aluminum oxide, the CNTs were synthesized with alignment, as shown in Figs. $4 a$ and $b$. But in the cases of calcium oxide and manganese oxide, CNTs were not as aligned as they are for the sample shown in Fig. 4c. Even when the same portion of catalysts was used for aligned CNTs, the yields of CNTs were $6000 \%, 500 \%, 200 \%$ and $50 \%$, respectively, in order of magnesium oxide, aluminum oxide, calcium oxide and manganese oxide. According to NFPA 704, reactivity, such as explosive decomposition, differs according to the nitrate form of support. It could be assumed that this would lead to various statuses of the catalysts, such as loading amounts on and attachment with supports, and, therefore, that the yields and alignments of the CNTs would be affected according to the types of the support materials.

To control the length of the aligned CNTs, we used diverse amounts of $\mathrm{Mo}-\mathrm{Fe}$ in the $\mathrm{MgO}$ supports. When the molar weights of $\mathrm{MgO}$ were fixed at 1.000 , the molar weights of Mo were in a range from 0.009 to 0.058 , and those of Fe were modified from 0.038 to 0.127 , as presented in Table 1. Fig. 5 shows the morphologies of the CNTs that were grown on diverse molar portions of catalysts; amounts of Mo-Fe decreased from top to bottom. The yields of CNTs were 5000, 

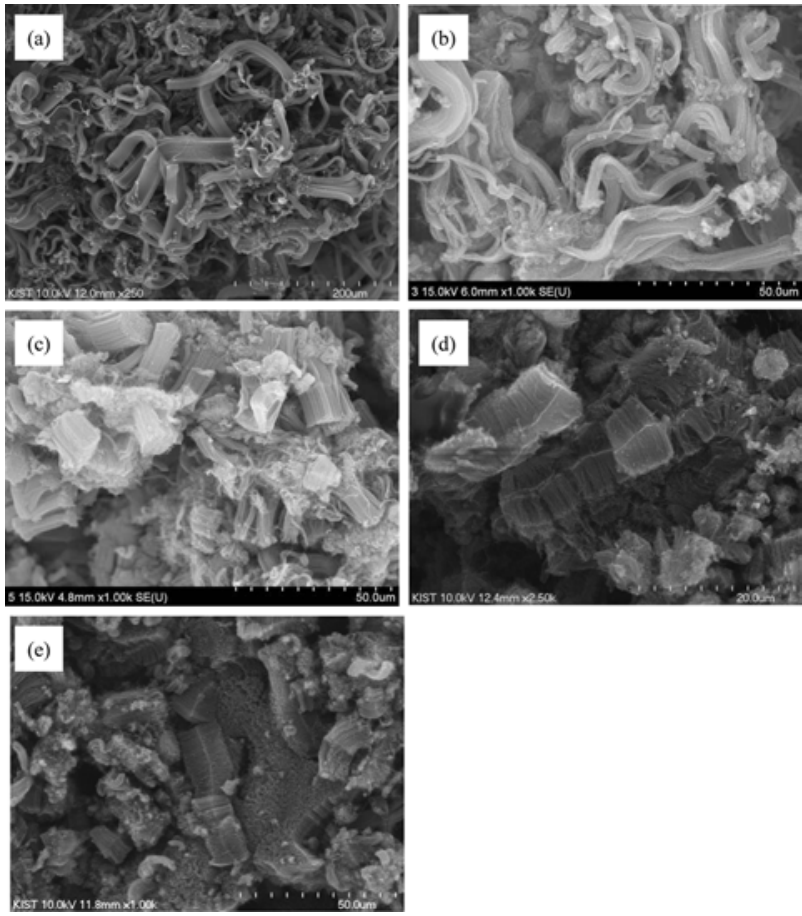

Fig. 5. Images of scanning electron microscope for as-grown carbon nanotubes with different contents of $\mathrm{Mo}$ and $\mathrm{Fe}$ in catalysts ; (a) $\mathrm{Mo} / \mathrm{Fe}=$ $0.058 / 0.127$, (b) $\mathrm{Mo} / \mathrm{Fe}=0.029 / 0.127$, (c) $\mathrm{Mo} / \mathrm{Fe}=0.015 / 0.063$, (d) $\mathrm{Mo} / \mathrm{Fe}=$ $0.011 / 0.048$ and $(\mathrm{e}) \mathrm{Mo} / \mathrm{Fe}=0.009 / 0.038$

$3000,1000,500$ and $300 \mathrm{wt} \%$ in the order shown in Figs. 5ae. The CNTs in the entire range of molar ratios shown in Fig. 5 seemed to be aligned. Even for low contents of Mo and Fe, such as $0.009 \mathrm{Mol}$ and $0.038 \mathrm{Mol}$ compared to $\mathrm{MgO}$, almost all of the CNTs shown in Fig. 5e seem to be aligned and the $\mathrm{MgO}$ supports, which look like white lines, are located in the center of the both-side grown, aligned CNTs. The CNTs may have become well-aligned on $\mathrm{MgO}$ supports with sizes larger than $50 \mu \mathrm{m}$, as shown in Fig. 5d. The measurement of the length of the aligned CNTs was achieved through analysis of the SEM images; it came out that the lengths of bundled CNTs were 5-10 $\mu \mathrm{m}, 10-20 \mu \mathrm{m}, 20-40 \mu \mathrm{m}, 40-60 \mu \mathrm{m}$, and more than $100 \mu \mathrm{m}$, in order of the increment of the catalyst contents seen in Figs. a-f. The molar ratios of $\mathrm{Mo}$ to $\mathrm{Mg}$ and Fe to $\mathrm{Mg}$ were from 1.0 to 1.2 and from 0.01 to 0.1 in previous works [11-14], whereas those of Mo to $\mathrm{Mg}$ and Fe to Mo were from 0.01 to 0.06 and from 0.04 to 0.14 in our work. In
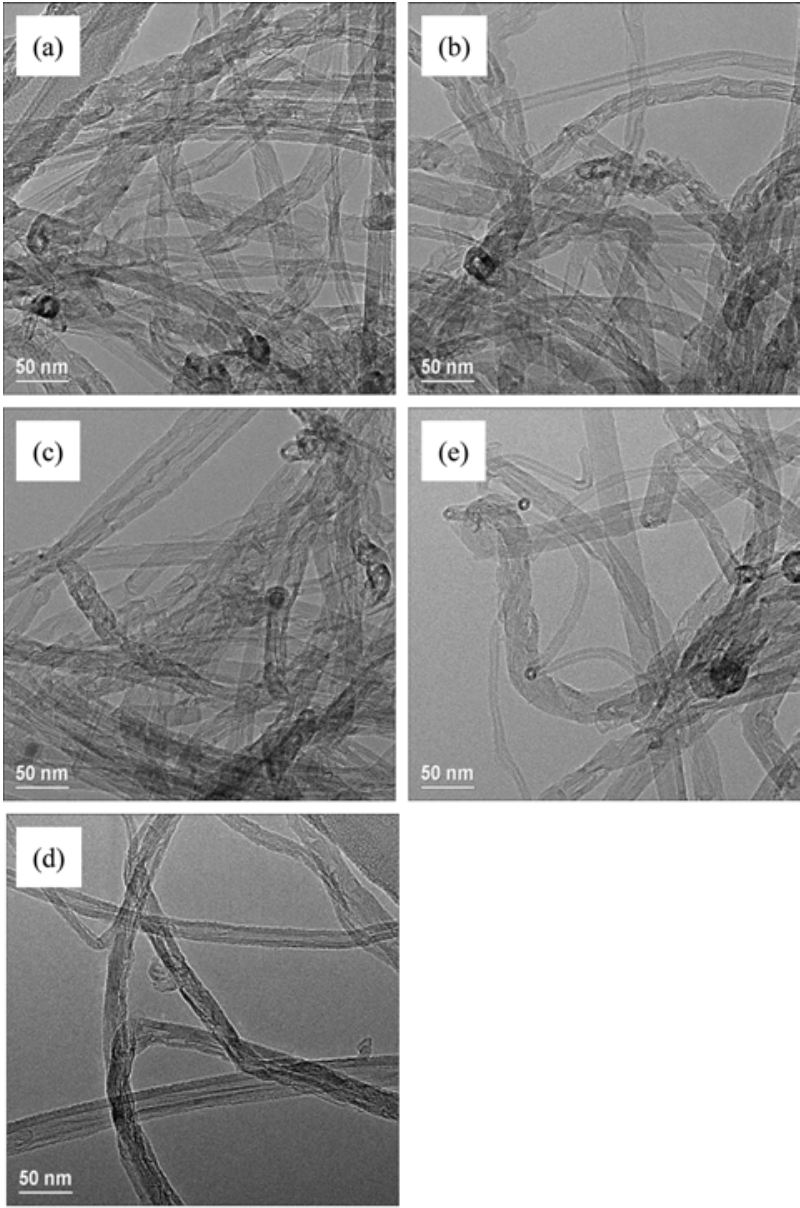

Fig. 6. Transmission electron microscope images of carbon nanotubes grown with different contents of $\mathrm{Mo}$ and $\mathrm{Fe}$ in catalysts; (a) $\mathrm{Mo} / \mathrm{Fe}=$ $0.058 / 0.127$, (b) $\mathrm{Mo} / \mathrm{Fe}=0.029 / 0.127$, (c) $\mathrm{Mo} / \mathrm{Fe}=0.015 / 0.063$, (d) $\mathrm{Mo} / \mathrm{Fe}=$ $0.011 / 0.048$ and $(\mathrm{e}) \mathrm{Mo} / \mathrm{Fe}=0.009 / 0.038$.

short, previous works [11-14] used a catalyst with high Mo content; on the other hand, we used a catalyst with low Mo content. In cases of high content of Mo in the catalyst, high temperature was needed to grow CNTs, because the melting point of Mo is higher than $2000^{\circ} \mathrm{C}$. Wang et al. [10] and others [11-14] carried out experiments to obtain aligned CNTs at more than $900^{\circ} \mathrm{C}$ with flow of methane gas; however, we could have aligned CNTs at less than $700^{\circ} \mathrm{C}$ with a flow of ethylene gas instead of methane gas.

Table 1. Molar ratio of catalysts for aligned CNTs

\begin{tabular}{cccccc} 
& Al_CNT-1 & Al_CNT-2 & Al_CNT-3 & Al_CNT-4 & Al_CNT-5 \\
\hline Mg & 1 & 1 & 1 & 1 & 1 \\
Mo & 0.009 & 0.011 & 0.015 & 0.029 & 0.058 \\
Fe & 0.038 & 0.048 & 0.063 & 0.127 & 0.127 \\
Yield & $300 \%$ & $500 \%$ & $1000 \%$ & $3000 \%$ & $6000 \%$ \\
Length & $5-10 \mu \mathrm{m}$ & $10-20 \mu \mathrm{m}$ & $40-60 \mu \mathrm{m}$ & $>100 \mu \mathrm{m}$ & $>100 \mu \mathrm{m}$
\end{tabular}

CNTs: carbon nanotubes. 


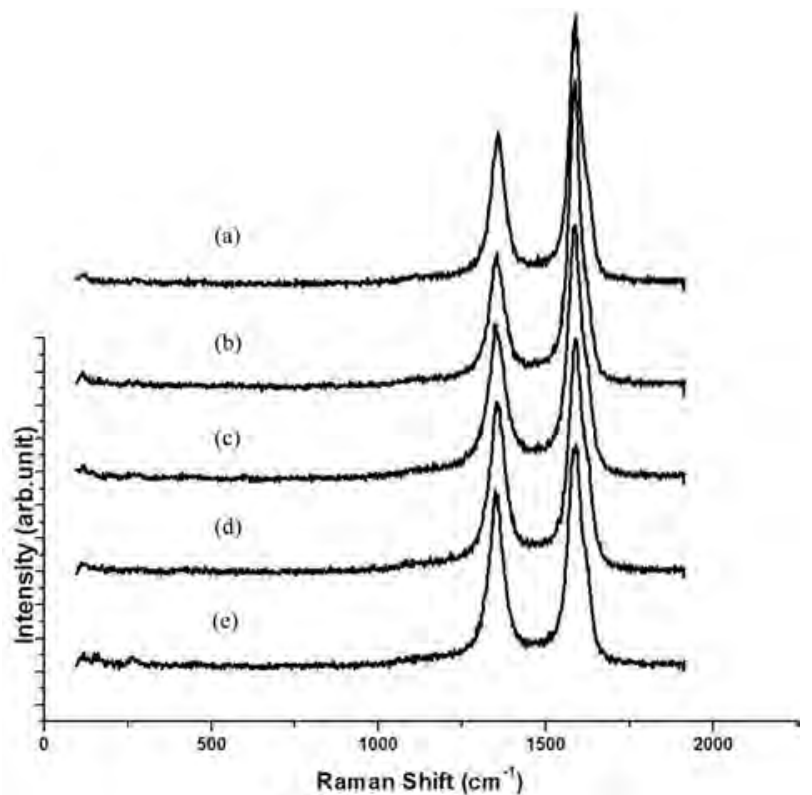

Fig. 7. Raman spectra of carbon nanotubes grown with different contents of $\mathrm{Mo}$ and $\mathrm{Fe}$ in catalysts: (a) $\mathrm{Mo} / \mathrm{Fe}=0.058 / 0.127$, (b) $\mathrm{Mo} / \mathrm{Fe}=$ $0.029 / 0.127$, (c) $\mathrm{Mo} / \mathrm{Fe}=0.015 / 0.063$, (d) $\mathrm{Mo} / \mathrm{Fe}=0.011 / 0.048$ and (e) $\mathrm{Mo} /$ $\mathrm{Fe}=0.009 / 0.038$.

TEM was used to measure the distribution and average diameters of CNTs. The diameter distributions of all CNTs turned out to be around $10-30 \mathrm{~nm}$ and the average diameters were from 15-20 nm, as shown in Fig. 6. The diameters of the CNTs shown in Fig. $5 \mathrm{f}$ were expected to be smaller than those of other samples (Figs. 5 a-e), but were identical in the range of 10 to $30 \mathrm{~nm}$. These results were similar to our previous results (not published), in which the diameters of the CNTs were around 5-1 nm when they were grown at more than $850^{\circ} \mathrm{C}$ with flow of methane; however, with the same catalysts, the diameters of CNTs were about from 10 to $30 \mathrm{~nm}$ when they were synthesized at $650{ }^{\circ} \mathrm{C}$ with flow of ethylene. Fig. 7 shows Raman spectra of the as-grown CNTs; these results are identical to those shown in Fig. 5. The values of $\mathrm{I}_{\mathrm{G}} / \mathrm{I}_{\mathrm{D}}$ were determined to be 1.3, 1.5, 1.4, 1.6 and 1.8 from Figs. 5 a-e, respectively, making them as low as those of commercially produced CNTs.

\section{Conclusions}

In this study, we showed the effects of the parameters of the preparing conditions and the compositions of the catalysts on the alignment and length control of CNTs. The key point to make CNTs align was high temperature for the calcination of catalysts, in other words, in our study a temperature of more than $800^{\circ} \mathrm{C}$. We controlled the length of the aligned CNTs by controlling the composition of Mo-Fe. When there was high content of Mo and Fe, such as 0.06 and 0.14 mol (molar weight of $\mathrm{Mg}$ was fixed at 1), these conditions made the CNTs align, because numerous metal nanoparticles sufficiently existed on the surfaces of the supports. But, even when the portions of Mo and Fe were reduced to as low as 0.010 and $0.040 \mathrm{~mol} \%$, short and aligned CNTs were obtained in this study.

\section{Acknowledgments}

This research was supported by a grant from the Fundamental R\&D Program for "Core Technology of Materials" and "World Premier Materials," funded by the Ministry of Knowledge Economy, Republic of Korea.

\section{References}

[1] Dresselhaus MS, Dresselhaus G, Jorio A. Unusual properties and structure of carbon nanotubes. Ann Rev Mater Res, 34, 247 (2004) http://dx.doi.org/10.1146/annurev.matsci.34.040203.114607.

[2] Treacy MMJ, Ebbesen TW, Gibson JM. Exceptionally high Young's modulus observed for individual carbon nanotubes. Nature, 381, 678 (1996). http://dx.doi.org/10.1038/381678a0.

[3] Dai H, Wong EW, Lieber CM. Probing electrical transport in nanomaterials: conductivity of individual carbon nanotubes. Science, 272, 523 (1996). http://dx.doi.org/10.1126/science. 272.5261 .523

[4] Wong EW, Sheehan PE, Lieber CM. Nanobeam mechanics: elasticity, strength, and toughness of nanorods and nanotubes. Science, 277, 1971 (1997). http://dx.doi.org/10.1126/science.277.5334.1971.

[5] Ziegler KJ, Gu Z, Peng H, Flor EL, Hauge RH, Smalley RE. Controlled oxidative cutting of single-walled carbon nanotubes. J Am Chem Soc, 127, 1541 (2005). http://dx.doi.org/10.1021/ja044537e.

[6] Shuba MV, Paddubskaya AG, Kuzhir PP, Maksimenko SA, Ksenevich VK, Niaura G, Seliuta D, Kasalynas I, Valusis G. Soft cutting of single-wall carbon nanotubes by low temperature ultrasonication in a mixture of sulfuric and nitric acids. Nanotechnology, 23, 495714 (2012). http://dx.doi.org/10.1088/0957. 4484/23/49/495714.

[7] Marshall MW, Popa-Nita S, Shapter JG. Measurement of functionalised carbon nanotube carboxylic acid groups using a simple chemical process. Carbon, 44, 1137 (2006). http://dx.doi. org/10.1016/j.carbon.2005.11.010.

[8] Ciambelli P, Sannino D, Sarno M, Leone C, Lafont U. Effects of alumina phases and process parameters on the multiwalled carbon nanotubes growth. Diamond Relat Mater, 16, 1144 (2007). http:// dx.doi.org/10.1016/j.diamond.2007.01.007.

[9] Mendoza E, Rodriguez J, Li Y, Zhu YQ, Poa CHP, Henley SJ, Romano-Rodriguez A, Morante JR, Silva SRP. Effect of the nanostructure and surface chemistry on the gas adsorption properties of macroscopic multiwalled carbon nanotube ropes. Carbon, 45, 83 (2007). http://dx.doi.org/10.1016/j.carbon.2006.08.001.

[10] Wang XB, Liu YQ, Zhu DB. Two- and three-dimensional alignment and patterning of carbon nanotubes. Adv Mater, 14, 165 (2002). http://dx.doi.org/10.1002/1521-4095(20020116)14:2<165::AIDADMA165>3.0.CO;2-3.

[11] Motiei M, Calderon-Moreno J, Gedanken A. Forming multiwalled carbon nanotubes by the thermal decomposition of $\mathrm{Mo}(\mathrm{CO})_{6}$ Chem Phys Lett, 357, 267 (2002). http://dx.doi.org/10.1016/ S0009-2614(02)00519-5.

[12] Ning Y, Zhang X, Wang Y, Sun Y, Shen L, Yang X, Van Tendeloo G. Bulk production of multi-wall carbon nanotube bundles on sol-gel prepared catalyst. Chem Phys Lett, 366, 555 (2002). http:// dx.doi.org/10.1016/S0009-2614(02)01647-0. 
[13] Li Y, Zhang X, Tao X, Xu J, Chen F, Huang W, Liu F. Growth mechanism of multi-walled carbon nanotubes with or without bundles by catalytic deposition of methane on $\mathrm{Mo} / \mathrm{MgO}$. Chem Phys Lett, 386, 105 (2004). http://dx.doi.org/10.1016/j.cplett.2003.12.128.

[14] Xu JM, Zhang XB, Li Y, Tao XY, Chen F, Li T, Bao Y, Geise HJ. Preparation of $\mathrm{Mg} 1-\mathrm{xFexMoO} 4$ catalyst and its application to grow MWNTs with high efficiency. Diamond Relat Mater, 13, 1807 (2004). http://dx.doi.org/10.1016/j.diamond.2004.04.011.
[15] Ma Z, Shi J, Song Y, Guo Q, Zhai G, Liu L. Carbon with high thermal conductivity, prepared from ribbon-shaped mesosphase pitchbased fibers. Carbon, 44, 1298 (2006). http://dx.doi.org/10.1016/j. carbon.2006.01.015.

[16] Moon YK, Lee J, Lee JK, Kim TK, Kim SH. Synthesis of lengthcontrolled aerosol carbon nanotubes and their dispersion stability in aqueous solution. Langmuir, 25, 1739 (2009). http://dx.doi. org/10.1021/la8031368. 